\title{
XXIV. A high pressure spark-gap used in connexion with the Tesla coil
}

\author{
F.J. Jervis-Smith M.A. F.R.S.
}

To cite this article: F.J. Jervis-Smith M.A. F.R.S. (1902) XXIV. A high pressure spark-gap used in connexion with the Tesla coil , Philosophical Magazine Series 6, 4:20, 224-226, DOI: 10.1080/14786440209462838

To link to this article: http://dx.doi.org/10.1080/14786440209462838

曲 Published online: 15 Apr 2009.

Submit your article to this journal $\sqsubset \pi$

Џ Article views: 2

Q View related articles $\asymp$ 


\section{[ 224 ]}

XXIV. A High Pressure Spark-Gap used in connexion with the Tesla Coil. By F. J. Jervis-Smith, M.A., F'R.S.*

$\mathbf{I}^{\mathrm{N}}$ $\mathrm{N}$ October $1896 \mathrm{I}$ showed that an $x$-ray-photo could be produced by means of an exhausted bulb having no terminals, and in January 1897 the relationship between the position of maximum activity at the bulb and the discharge from a Tesla inductor was described. The references are p. 594, vol. liv. and p. 294, vol. 1v. 'Nature.' Again returning to experiments with exhausted bulbs having no terminals, I wished to improve the Tesla inductor formerly used by me. When a spark-gap is employed in air at normal or less than normal pressure, the sparks often leap from bal] to ball, not by the nearest path, but through a rather long one of curved form [the ends of the curved path often terminating in the equatorial regions of the two balls], the discharge from the secondary coil at the same time being somewhat reduced. With this before one it seemed highly probable that far better results would be obtained if the spark-gap were subjected to pressure.

In order to put this to the test a spark-gap was constructed as shown in fig. 1, where B is a glass vessel closed with a
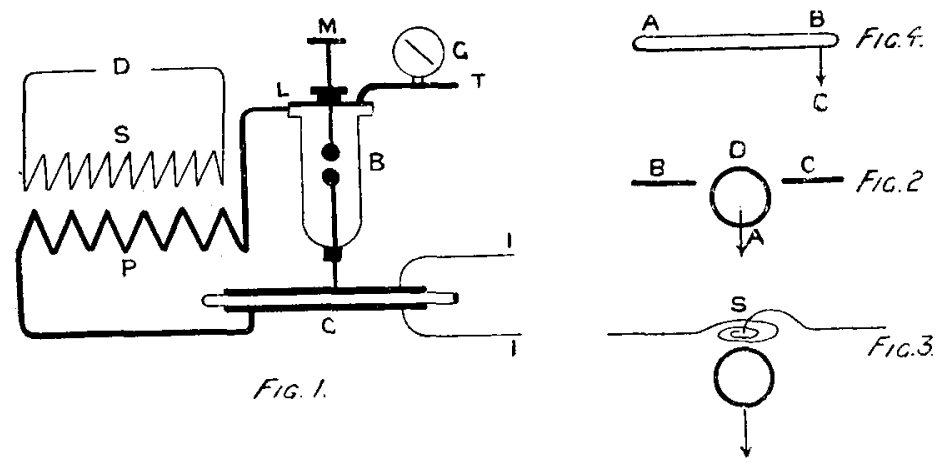

metal lid L, provided with a stuffing-box through which al screwed rod can be moved by means of a micrometer head M; the rod carries the upper ball, the lower ball is attached to a rod which passes through a plug in the bottom of the vessel; a tube $T$ and a pressure-gauge $G$ are attached to the lid, and also to an air force-pump (not shown) ; one end of the primary coil $\mathrm{P}$ is attached to the lid and the other end to the condenser $\mathrm{C}$. The two sides of the condenser are connected to the secondary of an induction-coil, by the wires I, I. S is

* Communicated by the Author. 
the secondary of the Tesla inductor, and the discharge takes place at D. In one experiment the balls in B were placed $0.3 \mathrm{~cm}$. apart, and the distance between the terminals at D was $7 \cdot 0 \mathrm{~cm}$. The pressure was normal.

When the induction-coil was started only a luminous brush of very thin sparks crossed at $D$. The distances remaining the same in B and at $D$ the pressure in $B$ was raised to $75 \mathrm{~cm}$. of mercury; shortly before this pressure was reached, a torrent of thick sparks passed at $\mathrm{D}$, at the same time the sparks in $\mathrm{B}$ became compact and exceedingly bright. On removing the pressure the discharge returned to its former condition. Some of the effects produced by the discharge, though by no means of great length in air, were as follows:-

A vulcanite tube $0.45 \mathrm{~cm}$. thick in the wall was placed in paraffin oil, a wire from one terminal being placed within it, and outside it was placed a wire from the other terminal; on putting on the current the vulcanite was instantly perforated by the discharge.

Next a piece of plate-glass $0.4 \mathrm{~cm}$. thick was placed in the oil, the terminals being placed face to face on either side of it.

The instant the current was put on the glass was perforated without being cracked. On replacing the thick glass by a sheet of half the thickness, and repeating the experiment, a nearly round hole $(0 \cdot 2 \mathrm{~cm}$. in diameter) was made by the discharge.

In each case the conductor in contact with the glass was pointed. A thick piece of plate-glass was also cut through and divided into two parts by means of the discharge. The sheet of glass was placed on a sheet of tinfoil in a flat ressel, such as a photographic developing dish, and covered to the depth of about $2 \mathrm{~cm}$. with oil, the foil was comnected to one terminal, then on ruling a line with the other terminal on the plate-glass as rapidly as the hand could move it, the glass was found to be cut throngh under along the path of the terminal.

The discharge so produced, by the addition of the bigh pressure spark-gap, is very effective when used to excite the Röntgen effects in exhausted tubes and bulbs having no terminals. A bulb (fig. 2) was placed in the line of discharge, the distance between $B$ and $C$ being so arranged that but little discharge passed before the introduction of the bulb; when the apparatus was in action a vivid green glow was produced on the lower side of the bulb at $A$. In my early experiments in $1896 \mathrm{I}$ used bulbsiof about $4 \mathrm{~cm}$. in diameter. The pictures were fairly good. I now find that in order to obtain sharp definition the bulb should be small, about $1.5 \mathrm{~cm}$.

Phil. Mag. S. 6. Vol. 4. No. 20. Aug. 1902. 
in diameter, and placed about $17 \mathrm{~cm}$. above the object to be $x$-ray-graphed. [Time of exposure two to three minutes.]

Another way (fig. 3) of exciting the effects is to place a flat spiral of wire $S$ above the bulb, the spiral formmg a portion of the secondary circuit of the Tesla inductor, provided with a spark-gap having spherical terminals.

If a long exhausted tube (fig. 4) $(30 \mathrm{~cm}$. long, $1.5 \mathrm{~cm}$. diam.) be excited in any of the ways mentioned, at $A$, and a conductor be placed close to or in contact with the tube at $\mathrm{B}$, then the $x$-ray effect will be found opposite to $\mathrm{B}$, acting approximately in the direction C.

'The apparatus here described is now being reconstructed so that much greater pressures may be used in the spark-gap vessel, but even with the pressures already reached the discharge from the secondary of the Tesla-coil is enormously increased.

June 18, 1902.

P.S.-I also find that the high-pressure spark-gap, when placed in the secondary of an ordinary induction-coil, increases its effects considerably when used as a generator of Hertz waves. A pressure of one atmosphere alters the length of a spark between brass balls from $2 \cdot 5 \mathrm{~cm}$. to $0.75 \mathrm{~cm}$.

July 12,1902 .

XXV. The Steady Temperatures of a Thin Rod. By JAMEs W. PEck, M.A., Arnott and Thomson Demonstrator in Plysics in the University of Glasgow*.

rTHE well-known Fourier problem referred to in this paper 1 may be briefly stated as follows:-A homogeneous rod of small cross-section and great length has one end maintained at a constant temperature greater than that of the medium in which the rod is placed. By lateral radiation into this medium (also kept at a constant temperature) the rod acquires a steady distribution of temperature, diminishing as we go along the bar from the heated end. If $\mathrm{V}$ denote the temperature of the hot end (that of the medium being taken as zero), $e$ the emissivity (conducibilité cxtérieure) of the surface of the bar, $k$ the conductivity of the material, $s$ the cross-section (uniform), $p$ the perimeter, then $v$ the temperature at the distance $x$ from the hot end is given by $\dagger$

$$
v=\mathrm{V} \exp \left(-x \sqrt{\frac{e p}{k s}}\right) \cdot . \cdot . \cdot
$$

* Communicated by Prof. A. Gray, F.R.S.

$\uparrow$ Fourier, Théorie Analytique de la Chaleur, p. 55, Darboux's edition. 